Article

\title{
Optimal Conductor Size Selection in Distribution Networks with High Penetration of Distributed Generation Using Adaptive Genetic Algorithm
}

\author{
Zhenghui Zhao * ${ }^{\mathbb{D}}$ and Joseph Mutale \\ School of Electrical \& Electronic Engineering, University of Manchester, Sackville Street, Manchester M13 9PL, \\ UK; j.mutale@manchester.ac.uk \\ * Correspondence: zhenghui.zhao@postgrad.manchester.ac.uk
}

Received: 15 April 2019; Accepted: 28 May 2019; Published: 30 May 2019

check for updates

\begin{abstract}
The widespread deployment of distributed generation (DG) has significantly impacted the planning and operation of current distribution networks. The environmental benefits and the reduced installation cost have been the primary drivers for the investment in large-scale wind farms and photovoltaics (PVs). However, the distribution network operators (DNOs) face the challenge of conductor upgrade and selection problems due to the increasing capacity of DG. In this paper, a hybrid optimization approach is introduced to solve the optimal conductor size selection (CSS) problem in the distribution network with high penetration of DGs. An adaptive genetic algorithm (AGA) is employed as the primary optimization strategy to find the optimal conductor sizes for distribution networks. The aim of the proposed approach is to minimize the sum of life-cycle cost (LCC) of the selected conductor and the total energy procurement cost during the expected operation periods. Alternating current optimal power flow (AC-OPF) analysis is applied as the secondary optimization strategy to capture the economic dispatch (ED) and return the results to the primary optimization process when a certain conductor arrangement is assigned by AGA. The effectiveness of the proposed algorithm for optimal CSS is validated through simulations on modified IEEE 33-bus and IEEE 69-bus distribution systems.
\end{abstract}

Keywords: distributed power system; power system economic; optimal power flow; distributed generation (DG); genetic algorithm (GA)

\section{Introduction}

Nowadays, the large-scale installation of distribution generation (DG) of different types, including wind and photovoltaic (PV) farms, has significantly impacted the operation and planning of low voltage networks. The International Renewable Energy Agency (IRENA) reported that global renewable energy prices would be reduced to the cost range of traditional fossil fuels generation [1]. Most developed countries have launched their plans to support the development of renewable energies due to their environmental benefits. In the UK, for instance, a contract for difference (CfD) mechanism was introduced to improve the economic competitiveness of renewable resources in the electricity market [2]. However, increasing investment in DGs introduces new challenges to the distribution network operators (DNOs) due to the natural characteristic of PV and wind resources, namely, poor predictability and variability of output. Power losses, voltage profiles and frequency of the power system are often considered as the major impacts and factors in distribution networks with high penetration of DGs [3,4]. The rapid decline in the cost of renewable technologies has promoted the rapid integration of DGs at the distribution level. The maximum current carrying capacity of conductors is expected to satisfy the potential output of installed DGs and the increasing load demands. 
Meanwhile, the life-cycle cost (LCC) of the chosen conductors is also a significant factor that needs to be assessed since the objective of the DNOs is to provide a cost-effective service in the competitive market. Therefore, a judicious choice is that the selected conductors can satisfy the long-term load growth in the networks and achieve the optimal economic balance between the infrastructure investment and the energy procurement saving from consuming the installed DGs (the PV and wind DGs are commonly considered as zero marginal cost generation plants).

The common conductor size selection (CSS) problems have been widely researched and investigated in the past decades. Funkhouser and Huber [5] firstly introduced the approach for determining economical conductor sizes for distribution networks. The approach found the minimized investment of the conductor combination in a $13 \mathrm{kV}$ distribution network and considered the voltage regulation and short-circuit current safety requirement. The economic model of conductors was carefully established in the approach, where the labour cost, material cost and installation cost were fully considered in the paper. However, most of the costs such as the annual costs of energy losses and energy price applied in the papers were fixed, thereby failing to reflect operating scenarios in real power systems. In [6], a practical approach to the CSS was proposed for utility engineers. The approach considered the maximum allowable voltage drop and load growth as the objective in the cable selection and can achieve the optimal results quickly by a heuristic method. However, the method ignored the economic objective and can only be applied in pure radial distribution networks due to the simplified power flow analysis strategy. In [7], the authors maximized the total financial saving in conductor material and energy losses. However, the proposed approach used the same conductor type for each branch in the networks. The judicious CSS approach is expected to allocate the optimal conductor type to different branches in the networks since the various load profiles at each feeder results in different burdens to each branch. A Mixed-Integer LP Approach was applied to solve the CSS problems by Franco et al. [8]. The approach used a linearization method to simplify the optimization process and guaranteed the accuracy and convergence speed. Recently, several studies [9-16] used heuristic and evolution algorithm to solve the CSS problems. In $[9,10]$, particle swarm optimization (PSO) was introduced to minimize the overall cost of power losses and the investment of selected conductors and reference [11-14] applied genetic algorithm (GA). In [15], a novel approach based on crow search algorithm (CSA) was proposed for optimal CSS problems in low voltage networks. The harmony search algorithm with a differential operator was applied in [16] to solve the optimal CSS problems and minimize the total capital investment in conductors and the energy losses cost.

The majority of the previous research of optimal CSS problems focused on minimizing the total cost of investment of conductors and the total energy losses. Various approaches and innovative algorithms have been introduced to improve the efficiency and accuracy of the same problems. However, few papers considered the participation of DGs in the optimal CSS problems. The large-scale installation of DGs and the declined levelized cost of renewable generation challenge the traditional optimal CSS strategy. Installed DGs in the distribution systems are often considered as zero marginal cost energy resources in the power operation analysis. In the distribution systems with high penetration of renewable generations, DNOs need to allocate suitable conductors to different branches to consume the available output of DGs, thus maximizing the economic benefits from renewable resources. Therefore, the selected conductors are expected to have enough current carrying capacity to satisfy the peak output of the installed DGs. On the other hand, the investment of conductors is also an important economic factor that needs to be considered. Therefore, DNOs find it difficult to identify the optimal conductor arrangement for the distribution system with high penetration DGs. During the CSS process, DNOs often face two opposite results: (1) excessive investment on the conductor selection; and (2) the selected conductors have insufficient capacity to consume available renewable resources, thus increasing the total energy procurement cost.

In this paper, we propose a hybrid optimization algorithm to solve the CSS problems in distribution systems with high penetration DGs. Adaptive genetic algorithm (AGA) and alternating current optimal power flow (AC-OPF) are employed together to find the optimal sizing of conductors to minimize 
the sum of the LCC of selected cables and the total energy procurement cost from traditional fossil fuels generation. The AGA in the proposed approach is designed to improve the convergence speed and avoid falling into the local optimum point of the CSS problems in distribution systems. This innovative GA restricts the initial population to satisfy the network operation constraints such a voltage regulation and conductors' maximum current carrying capacity in distribution systems, thus allowing an improved efficiency of the optimization process. The adaptive function in the proposed GA provides a dynamic mutation and crossover strategies to avoid a low convergence speed or falling in local optimum points. The AC-OPF is applied as a secondary optimization tool in the proposed approach to finding the optimal economic dispatch (ED) when the primary optimization assigns the selected conductor size at each branch. The proposed framework considers for the first time the potential cost conflict between the conductor LCCs and the costs of renewable resources curtailment when dealing with the CSS problems at distribution level, by using an improved AGA that specifically designs for the CSS problem. Moreover, a precise conductor investment and O\&M cost model is introduced in this paper to ensure the accuracy of the proposed framework.

The remaining parts of the paper are organized as follows. Section 2 presents the objective functions and constraints as well as the overall methodology. The network and data that are prepared for verifying the proposed algorithm are presented in Section 3, and numerical test results are also presented. Section 4 provides the main conclusions and future search plan.

\section{Problems Formulation}

The objective function of the proposed optimal CSS problem and the related mathematic formulations are presented in this section.

\subsection{Objective Function}

The aim of the optimal CSS problem is to allocate the suitable conductor type from the given inventories to each branch in the network, thus minimizing the sum of all conductor's LCCs, power losses costs and the total energy procurement costs during the expected operation years of the conductors. The optimal process is subject to common power system operation constraints such as voltage limits, thermal limits and power balance. LCC of a certain conductor $L C C_{l}$ includes the investment cost, operation cost and maintenance cost. In particular, the investment cost includes the purchasing costs of fixed assets, purchasing costs of accessories (such as towers, wood poles and insulators), design and installation costs and other costs (such as land acquisition fee). The operation cost of a certain distribution line in this paper is considered as the total power losses costs of this feeder during its whole life cycle. The maintenance cost of a certain distribution line in this paper includes inspection cost and recondition cost (recondition the conductors to eliminate the hidden trouble and ensure the stability of the conductors).

In this paper, we propose a lump sum payment of total asset purchasing costs to simplify the formulation, where the annual discount rate is not applied in the objective function. The investment costs $I C_{l}$, operation cost $O C_{l}$ and maintenance $\operatorname{cost} M C_{l}$ of a certain conductor $l$ can be expressed by Equations (1)-(3), then the LCC of this conductor can be expressed by Equation (4).

$$
\begin{gathered}
I C_{l}=A P_{l}+A C_{l}+I N_{l} \\
O C_{l}=\sum_{t}^{T} P L_{l}^{t} \times E P_{t} \\
M C_{l}=\left(I S P_{l} \times I S T+R E C_{l} \times R E T\right) \times T \\
L C C_{l}=A P_{l}+A C_{l}+I N_{l}+\sum_{t}^{T} P L_{l}^{t} \times E P_{t}+\left(I S P_{l} \times I S T+R E C_{l} \times R E T\right) \times T
\end{gathered}
$$


where $A P_{l}$ is the asset purchasing cost of the conductor $l, A C_{l}$ is the accessories purchasing cost of the conductor $l, I N_{l}$ is the installation cost of the conductor $l, P L_{l}^{t}$ is the total power losses of the conductor $l$ in the operation year $t, O C_{l}$ is the operation cost of the conductor $l, P L_{l}^{t}$ is the power losses of the conductor $l$ in the operation year $t, E P_{t}$ is the average energy procurement costs in operation year $t$ and $T$ is the expected life span of the conductor. $M C_{l}$ represents the life-cycle maintenance cost of the conductor $l, I S P_{l}$ is the inspection cost of the conductor l, ISP (times/year) is per year inspection times of the conductor $l, R E C_{l}$ is the recondition cost of the conductor $l, R E T$ (times/year) is the per year recondition times of the conductor $l$.

Since we consider the full life span economic performance of the conductors, the existing loads in the networks are expected to have an accepted load growth rate $\lg$. Instead of the fixed energy price that is applied in the majority of earlier research, we use a quadratic cost function to establish a dynamic energy price curve. The load at each bus $i$ with load growth $\lg$ and the generator cost function are expressed by Equations (5)-(7).

$$
\begin{gathered}
P_{D i}^{t}=P_{D i} \times(1+l g)^{(t-1)} \\
Q_{D i}^{t}=Q_{D i} \times(1+l g)^{(t-1)} \\
G C_{g i}=\alpha_{g i} \times P G_{g i}^{2}+\beta_{g i} \times P G_{g i}+\gamma_{g i}
\end{gathered}
$$

where $P_{D i}^{t}$ and $Q_{D i}^{t}$ are active and reactive load at feeder $i$ in the operation year $t . P_{i}$ and $Q_{i}$ are active and reactive load at bus $i$ in the first operation year. $\alpha_{g i}, \beta_{g i}$ and $\gamma_{g i}$ are cost coefficients for generator gi. $G C_{g i}$ and $P G_{g i}$ are generator cost and corresponding power output of generator $g i$.

AC-OPF analysis can be employed to obtain the energy procurement costs and confirm the precise power losses when each branch of the network is allocated with a particular type of conductor. Therefore, the objective function of the proposed CSS problems can be expressed by Equation (8).

$$
\min \sum_{t}^{T} \sum_{g}^{G} G C_{g}^{t}+\sum_{l}^{L}\left(A P_{l}+A C_{l}+I N_{l}+\sum_{t}^{T} P L_{l}^{t} \times E P_{t}+\left(I S P_{l} \times I S T+R E C_{l} \times R E T\right) \times T\right)
$$

subject to:

$$
\begin{gathered}
P_{i}^{t}=V_{i}^{t} \sum_{j=1}^{n} V_{j}^{t} Y_{i j} \cos \left(\theta_{i j}^{t}+\delta_{j}^{t}-\delta_{i}^{t}\right) \\
Q_{i}^{t}=V_{i}^{t} \sum_{j=1}^{n} V_{j}^{t} Y_{i j} \sin \left(\theta_{i j}^{t}+\delta_{j}^{t}-\delta_{i}^{t}\right) \\
P_{g i}^{t}-P_{D i}^{t}=P_{i}^{t} \\
Q_{g i}^{t}-Q_{D i}^{t}=Q_{i}^{t} \\
\sum_{i} P_{g i}^{t}-\sum_{i} P_{D i}^{t}=P_{\text {loss }}^{t} \\
\sum_{i} Q_{g i}^{t}-\sum_{i} Q_{D i}^{t}=Q_{\text {loss }}^{t} \\
V_{\text {min }} \leq V_{i}^{t} \leq V_{\max } \\
P_{g i, \min } \leq P_{g i}^{t} \leq P_{g i, \max } \\
Q_{g i, \min } \leq Q_{g i}^{t} \leq Q_{g i, \max } \\
\left|\delta_{i}-\delta_{j}\right| \leq\left|\delta_{i}-\delta_{j}\right|_{\text {max }}
\end{gathered}
$$


where, $P_{i}^{t}$ and $Q_{i}^{t}$ are the active and reactive power injected at bus $i$ at operation year $t, Y_{i j}$ is the admittance parameter of the distribution line between bus $i$ and bus $j . \theta_{i j}^{t}, \delta_{j}^{t}$ and $\delta_{i}^{t}$ are relevant phase angles. Expressions (15)-(18) indicate that voltage at each bus, power generation and phase angles are constrained by relevant limitations.

\subsection{Adaptive Genetic Algorithm}

GAs are one of the most popular optimization algorithms that are applied to solve complex optimization and adaptation problems. The basic principles of the GA technique are based on natural selection and were initially introduced by Holland in [17]. Traditional GA approach includes the process of creating initial population, selection, crossover and mutation. The best fitness value and its corresponding individual are obtained when the maximum number of iterations is reached, or the convergence criterion is satisfied. However, the performance of GA largely depends on presupposed control parameters such as crossover rate and mutation rate, where a poor choice of parameters may result in a premature convergence solution or low convergence speed [18-20]. The AGA with self-controlled parameters is widely researched and proved as one of the best solutions to deal with the problem of falling into the local optimum result or low convergence speed in common GA approach [21-23]. The proposed AGA in this paper is specifically designed for the aim of optimal CSS in the distribution power systems. Similar to the standard GA approach, a set of the initial population with $N_{p}$ chromosomes are created at the beginning of the approach. Each chromosome can be represented as $C_{i}=\left[c_{1}, c_{2}, c_{3}, \ldots, c_{D}\right]$, where $D$ is the number of genes in the chromosome $C_{i}$. In this paper, we assume the number of branches in the network is $N_{b}$ and the available types of conductors in the inventory is $N_{c}$. In the proposed AGA approach, $c_{i} \in\left[1, N_{c}\right]$ and the value of $c_{i}$ represents the CSS of branch $i$. Therefore, each chromosome represents one solution of CSS in the network, where each gene of chromosome related to the selection of its corresponding branch. For example, in a CSS problem, it is assumed that the system has ten branches and four different available types of conductors in the inventory. Then, based on the previous definitions, the number of branches $N_{b}$ equals to 10 and the number of available conductor types $N_{c}$ equals to 4 . For a random individual, it will have the chromosome like this " 31224244321 ", and each gene in the chromosome represents a choice of conductor type for the corresponding branch. In particular, the first gene in this chromosome indicates that the branch $c_{1}$ will be allocated as the type 3 conductor.

Double adaptive crossover rates, hybrid fitness value and self-adaptive mutation operator are innovatively introduced in this approach. Instead of the normal single fitness value structure in the standard GA approach, a hybrid fitness value is designed for the SSC problems since the individual who has the optimal fitness value is also required to satisfy the network constraints at the same time. We assume $f\left(C_{i}\right)$ is the fitness value of individual $C_{i}$ and $V\left(C_{i}\right)$ is the auxiliary fitness value of individual $C_{i}$. If the individual $C_{i}$ can satisfy the network constraints such as the voltage constraints and thermal constraints in the optimal power flow analysis, then $V\left(C_{i}\right)=1$; otherwise $V\left(C_{i}\right)=0$. The individuals that cannot survive in the network constraints test will be replaced by a new random individual that can satisfy the network constraints test. In the crossover operator, we assume two crossover rates: elite crossover rate $\mathrm{cr}_{\text {elite }}$ and standard crossover rate $\mathrm{cr}_{\text {sta }}$. The individual who has the best fitness value in the iteration $t$ is marked as $C_{b f}(t)$, where this individual can generate offspring with other individuals in the population with the probability $P C_{\text {elite }}$ prior. Then, the rest of the individuals will generate offspring following the standard GA crossover process with the probability $P C_{s t a}$. In self-adaptive mutation operator, two adaptive factors $\sigma_{n}$ and $\sigma_{m}$ are introduced to achieve the function of self-adaptive GA, and the factors are expressed by Equations (19)-(22).

$$
\begin{gathered}
\sigma_{n}(t)=\rho \times\left(1-10^{\left(\frac{-1}{\mu(t)}\right)}\right) \\
\mu(t)=\left|\frac{\text { avefitness }(t)-\text { avefitness }(t-1)}{\text { avefitness }(t-1)-\operatorname{avefitness}(t-2)}\right|
\end{gathered}
$$




$$
\left\{\begin{array}{c}
\sigma_{m}(t)=\varepsilon \times 10^{\left(\frac{\omega}{N_{\text {tole }}(t)}\right)} \\
N_{\text {tole }}(t)=N_{\text {tole }}(t-1)+1 ; \quad \begin{array}{c}
\text { if objevtive function maintain the same } \\
\text { best fitbess value at iteration } t+1
\end{array} \\
\text { if objevtive function obtain better fitness vaule } \\
\text { at iteration } t+1
\end{array}\right.
$$

where avefitness $(t)$ is the average fitness value of all population at iteration $t, N_{\text {tole }}$ is the count number of iterations above which the GA process cannot achieve a better fitness value and $\omega, \varepsilon, \rho$ are auxiliary factors supporting the adaptive factors. $\sigma_{n}(t)$ represents the stability of overall population and the is applied to the adapt the number of genes that need to be mutated in next iteration. $\sigma_{m}(t)$ is used here to help the proposed GA approach to escape the local optimum point, where this factor is related to the mutation rate in next iteration. The genes that are required to mutate in iteration $t$ and the mutation rate in iteration $t$ are expressed by Equations (23) and (24).

$$
\begin{gathered}
N_{\text {mut }}(t)=N_{b} \times \sigma_{n}(t) \\
P_{\text {mut }}(t)=\sigma_{m}(t)
\end{gathered}
$$

Equations (21) and (22) indicate that the mutation rate will continually increase when the proposed GA approach falls into a local optimum point and cannot generate better fitness value. However, the increasing mutation rate will reach the presupposed auxiliary index $\varepsilon(\varepsilon \in(0,1))$ to maintain the stability of the mutation operator. Further, the index $\omega$ in Equation (21) is designed as a presupposed index to control the variation speed of the mutation rate. Based on Equation (22), it is noted that the mutation rate will reset to the initial value when a better fitness value is captured. This function can efficiently secure the new best fitness value and allow the corresponding chromosome or genes to fully integrate to the population through the elite crossover process.

\subsection{Methodology}

The proposed hybrid CSS optimization approach contains two main mechanisms: AC-OPF study and AGA. AGA is applied as the primary optimization mechanism which is responsible for collecting the simulation results from the AC-OPF, exploring the best individual and updating the evolution strategy of the approach. AC-OPF is responsible for accessing the minimum energy costs of each individual in the population of every iteration. The detailed flow chart of the approach is shown in Figure 1. In particular, the framework follows the steps below:

(1) AGA module generates the initial population with the required number of the individuals.

(2) AGA module decodes the individuals and applies the decoded information to allocate the CSS. It is noted that each individual represents a unique CSS plan for the chosen distribution network.

(3) The CSS of each individual is captured and loaded to the AC-OPF optimization module and the LCC assessment module.

(4) The AC-OPF optimization module processes the power flow study of each individual by the relevant CSS plan. In order to capture the change of power losses due to the increasing load demand, the power flow study is operated $N$ times for each individual, where $N$ represents the expected operation years of the conductors. It is noted that the individuals that cannot survive in the requirement of minimal voltage constraints or thermal constraints are eliminated immediately and replaced by the one who can satisfy the relevant constraints. This process is prior to the fitness value calculation. Finally, for each survived individual in the current iteration, the sum of the power losses and the energy procurement costs during the expected operation years are obtained.

(5) For each individual in the current iteration, the LCC assessment module evaluates the LCC of each conductor and provides a system level LCCs data. The system level conductor LCCs here represent the sum of each conductor's life cycle cost in the network. 
(6) After the power flow analysis and calculation in the AC-OPF module and the LCC assessment module, the fitness value of each individual (sum of the system level conductor LCC, the total energy procurement costs and energy losses costs) is confirmed.

(7) After all individuals in the current iteration are assessed, the selection module is expected to find the best fitness value in this iteration and compare it with the present best fitness value.

(8) AGA module generates the adaptive crossover factor and adaptive mutation factor for the next iteration, where the factors are evaluated and decided by all individuals' fitness value of current and last iteration (explained in Section 2.2 already).

(9) Move to the next iteration or stop the process since the maximum number of iterations is reached or the convergence criterion is satisfied.

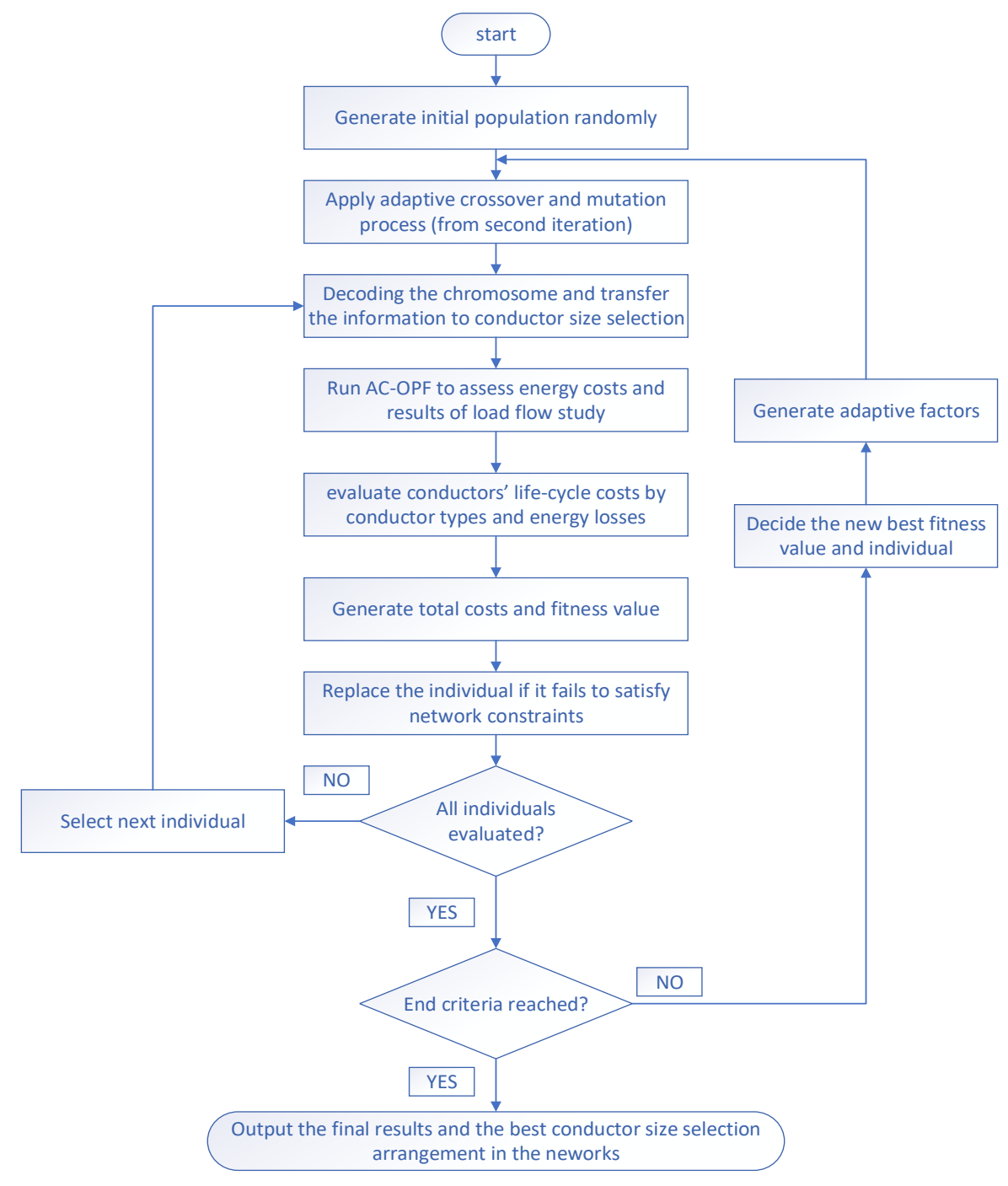

Figure 1. Flow chart of the proposed hybrid conductor size selection (CSS) optimization algorithm.

\section{Numerical Results}

The proposed hybrid optimal CSS approach is tested on the a 33-bus distribution network and a 69-bus distribution network in the numerical tests. In each test network, three distributed wind turbines with different available outputs are allocated at selected branches. The relevant parameters of the AGA used in this numerical test are summarized in Table 1. 
Table 1. Parameter of adaptive generic algorithm.

\begin{tabular}{cc}
\hline Parameter & Value \\
\hline Initial population & 100 \\
Length of chromosome & 32 \\
Initial elite crossover rate & $3 \%$ \\
Initial standard crossover rate & $85 \%$ \\
Initial mutation rate & $5 \%$ \\
Initial mutation genes & 1 \\
Auxiliary factor $\rho$ & 6 \\
Auxiliary factor $\varepsilon$ & 0.5 \\
Auxiliary factor $\omega$ & 2.2 \\
Maximum iterations & 300 \\
\hline
\end{tabular}

In order to identify the efficiency and the performance of the proposed AGA, the standard generic algorithm is applied in this paper for the aim of comparison, and the parameters used for the standard GA are shown in Table 2.

Table 2. Parameter of the standard generic algorithm.

\begin{tabular}{cc}
\hline Parameter & Value \\
\hline Crossover rate & $80 \%$ \\
Mutation rate & $5 \%$ \\
Mutation genes & 1 \\
Maximum iterations & 300 \\
\hline
\end{tabular}

The available conductor types in the inventory and the relevant specifications are listed in Table 3. It is noted that the data of the conductors are different between manufactories and the unit price of the conductors vary between different markets. We refer to several papers $[7,16,24]$ to provide this data.

Table 3. Specifications of proposed aluminum-conductor steel-reinforced (ACSR) conductors.

\begin{tabular}{ccccc}
\hline Conductor Type & $\boldsymbol{R}(\boldsymbol{\Omega} / \mathbf{k m})$ & $\mathbf{X}(\mathbf{\Omega} / \mathbf{k m})$ & $\boldsymbol{I}_{\text {max }} \mathbf{( A )}$ & $\mathbf{U P}(\mathbf{\$} / \mathbf{k m})$ \\
\hline Mole & 2.718 & 0.3740 & 70 & 90 \\
Squirrel & 1.376 & 0.3896 & 115 & 170 \\
Gopher & 1.098 & 0.3100 & 138 & 210 \\
Weasel & 0.9108 & 0.3797 & 150 & 260 \\
Ferret & 0.6795 & 0.2980 & 180 & 340 \\
Rabbit & 0.5441 & 0.3973 & 208 & 420 \\
Mink & 0.4546 & 0.2850 & 226 & 500 \\
Beaver & 0.3841 & 0.2795 & 250 & 590 \\
Raccoon & 0.3675 & 0.3579 & 260 & 630 \\
Otter & 0.3434 & 0.3280 & 270 & 770 \\
\hline
\end{tabular}

The parameters used to evaluate the LCC of the conductors are shown in Table 4. It is difficult to identify the precise installation and accessories costs of each conductor. However, we link those relevant costs with the unit wire purchase cost of conductors with different sizes. The detailed evaluation approach has been explained in Section 2.1. For example, if one of the branches in the network is allocated by the conductor with type Gopher, the LCC can be evaluated by express: $210(\$ / \mathrm{km}) \times$ length of conductor $(\mathrm{km}) \times(450 \%+100 \%+50 \%) \times[1+(75 \%+8 \% \times 12+5 \%) \times$ operation year $]$. 
Table 4. Cost parameters of conductor investment.

\begin{tabular}{cc}
\hline Parameter & Value \\
\hline Planning operation period & 20 years \\
Accessories cost & $450 \%$ wire cost \\
Design and Installation cost & $100 \%$ wire cost \\
Inspection cost & $75 \%$ wire costs (per year) \\
Recondition costs & $8 \%$ wire cost (per month) \\
Annual operation cost & $5 \%$ of total investment \\
\hline
\end{tabular}

(1) Case study of the 33-bus distribution network

The proposed CCS optimization approach is tested on a 33-bus network in this section, where three wind generators are connected to the network at branch 9, branch 18 and branch 26 . The single line diagram of this 33-bus distribution network is shown in Figure 2, and the relevant operation data and network constraints are listed in Table 5.

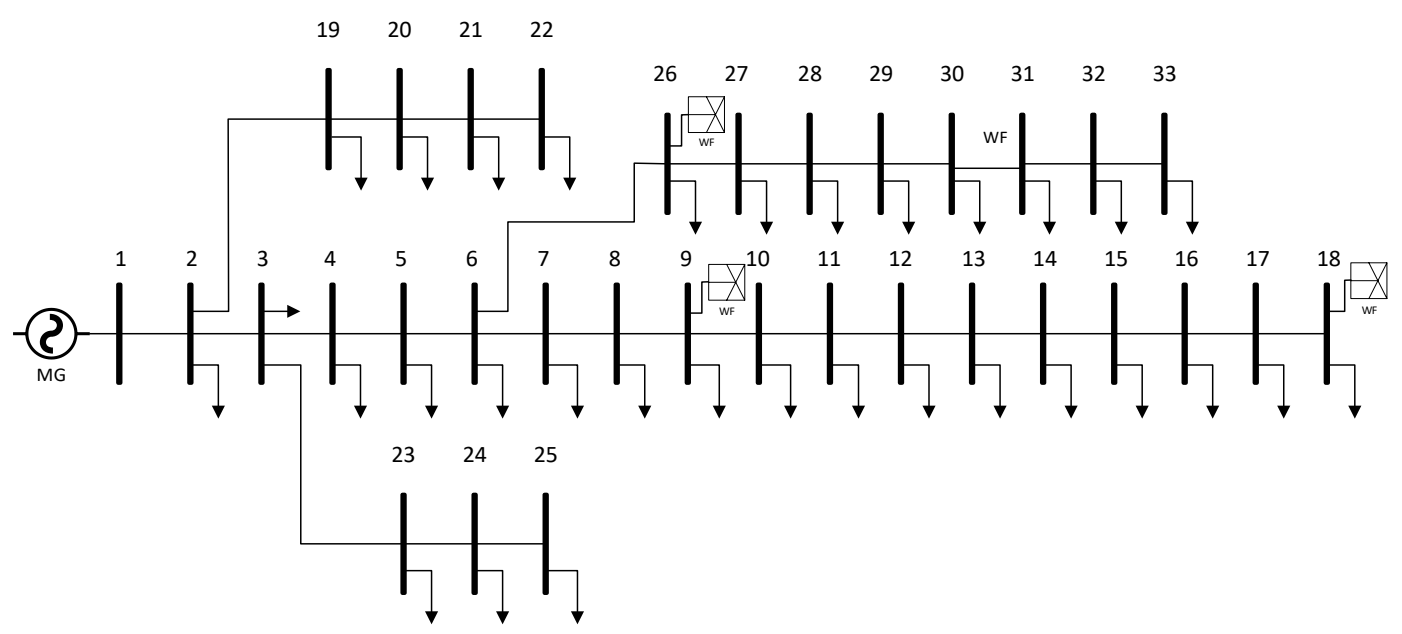

Figure 2. Single line diagram of the 33-bus distribution network.

Table 5. Parameters of the 33-bus network.

\begin{tabular}{cc}
\hline Parameter & Value \\
\hline Maximum voltage & 1.1 (p.u.) \\
Minimum voltage & 0.94 (p.u.) \\
Initial total active demand & $3.72 \mathrm{MW}$ \\
Initial total reactive demand & $1.16 \mathrm{MVar}$ \\
Load growth rate & $5 \% /$ year \\
Operation year & 20 years \\
Total branches & 32 \\
Maximum available output of wind farm at node 9 & $1.2 \mathrm{MW}$ \\
Maximum available output of wind farm at node 18 & $1.0 \mathrm{MW}$ \\
Maximum available output of wind farm at node 26 & $0.6 \mathrm{MW}$ \\
\hline
\end{tabular}

The quadratic generation cost function of the main generator connected at node 1 is expressed in Equation (25) and it is noted that we consider the wind farm as a zero marginal cost generator in this approach.

$$
e n_{\text {cost }}(\$ / M W h)=0.78 \times P G^{2}-2.1 \times P G+10.4
$$

where $P G$ is the power output of this generator and is within the limitation of its generation output $(0 \leq P G \leq 10 \mathrm{MW})$. 
A hybrid termination condition approach is used to identify the end of iterations. In particular, the algorithm will be terminated when either of the conditions is reached: (1) when there has been no improvement in the population for 100 iterations; or (2) when the GA reaches 300 generations. However, the results of 300 iterations are provided in all cases to ensure the continuity of the simulation by different cases.

The overall results of the proposed AGA optimal CSS for the selected 33-bus distribution network are shown in Figure 3. It is observed that the best fitness can be achieved after approximately 150 iterations. The mutation rate is self-adaptive during the process of the AGA, which is shown in Figure 4. It can be observed that the mutation rate is increased when the AGA cannot provide better fitness value and resets to zero when a better fitness value is achieved.

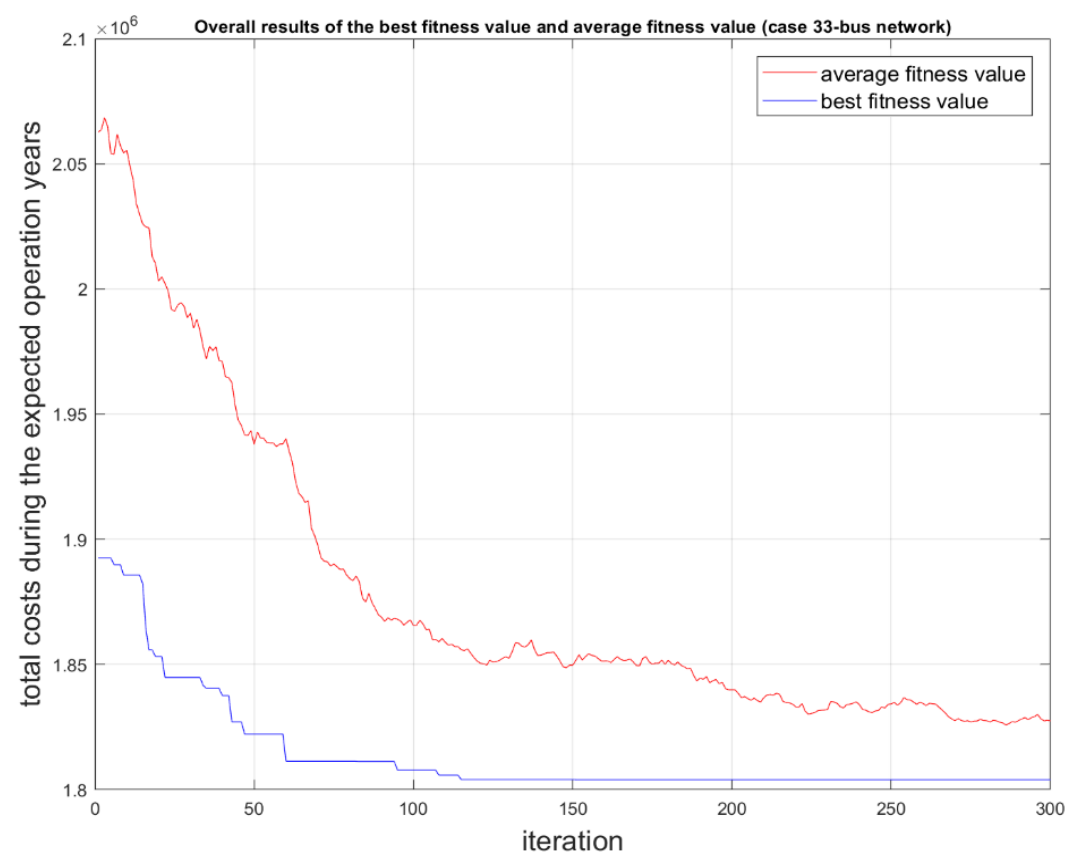

Figure 3. Overall results of the best fitness value and average fitness value (case 33-bus network).

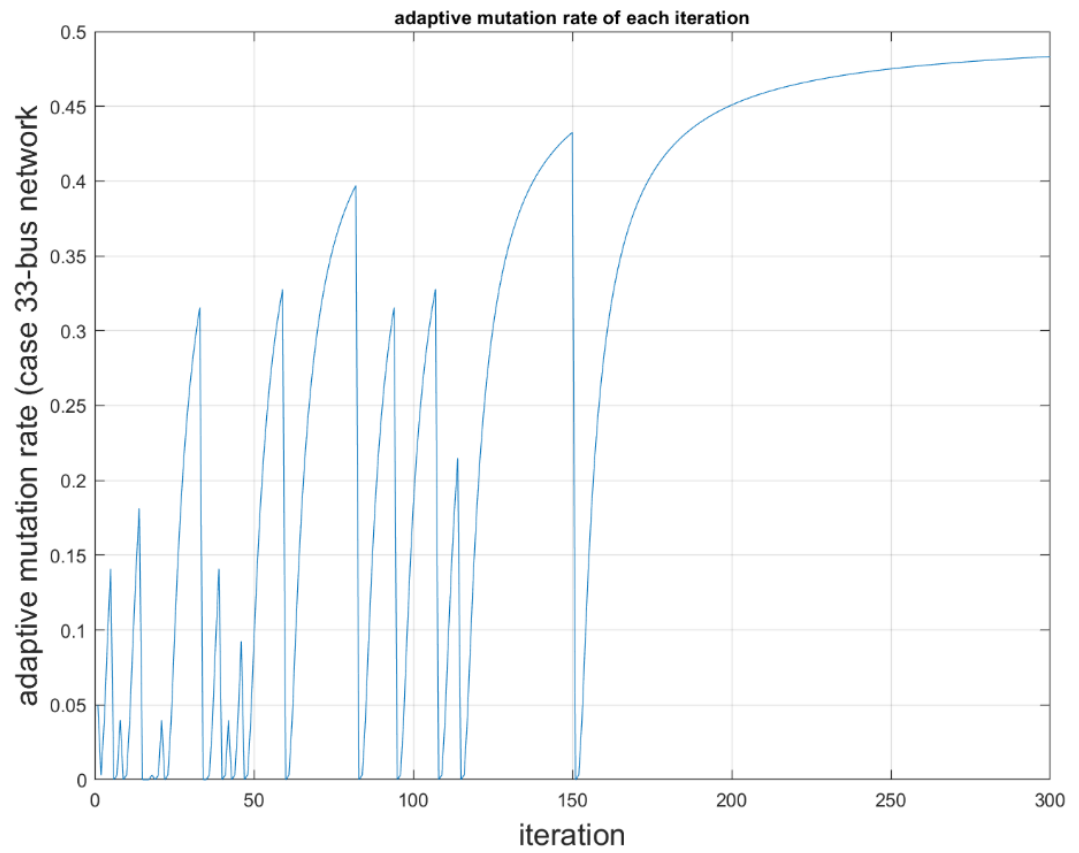

Figure 4. Adaptive mutation rate in each iteration (case 33-bus network). 
The detailed optimum results of CSS by two different approaches are shown in Table 6. After the decoding process, the best conductor type of each branch in the 33-bus network can be checked on this table.

Table 6. Best CSS for 33-bus distribution network. GA: genetic algorithm; and AGA: adaptive genetic algorithm.

\begin{tabular}{|c|c|c|c|c|c|c|}
\hline \multirow[t]{2}{*}{ Branch } & \multirow[t]{2}{*}{ From Node } & \multirow[t]{2}{*}{ To Node } & \multicolumn{2}{|c|}{$\begin{array}{l}\text { Initial Demand at Branch } \\
\text { Ending Node }(\mathrm{kW})\end{array}$} & \multirow{2}{*}{$\begin{array}{c}\text { Selected Conductor } \\
\text { Type Via Standard } \\
\text { GA }\end{array}$} & \multirow[t]{2}{*}{$\begin{array}{l}\text { Selected Conductor } \\
\text { Type Via AGA }\end{array}$} \\
\hline & & & $P$ & $Q$ & & \\
\hline 1 & 1 & 2 & 100 & 30 & Rabbit & Raccoon \\
\hline 2 & 2 & 3 & 90 & 20 & Mole & Mole \\
\hline 3 & 3 & 4 & 120 & 30 & Ferret & Ferret \\
\hline 4 & 4 & 5 & 60 & 30 & Mink & Raccoon \\
\hline 5 & 5 & 6 & 60 & 20 & Gopher & Mole \\
\hline 6 & 6 & 7 & 200 & 50 & Otter & Weasel \\
\hline 7 & 7 & 8 & 200 & 50 & Otter & Gopher \\
\hline 8 & 8 & 9 & 60 & 20 & Weasel & Mole \\
\hline 9 & 9 & 10 & 60 & 20 & Weasel & Gopher \\
\hline 10 & 10 & 11 & 45 & 30 & Otter & Gopher \\
\hline 11 & 11 & 12 & 60 & 35 & Mole & Mole \\
\hline 12 & 12 & 13 & 60 & 35 & Mole & Mole \\
\hline 13 & 13 & 14 & 120 & 30 & Ferret & Gopher \\
\hline 14 & 14 & 15 & 60 & 20 & Ferret & Weasel \\
\hline 15 & 15 & 16 & 60 & 20 & Mole & Weasel \\
\hline 16 & 16 & 17 & 60 & 20 & Squirrel & Rabbit \\
\hline 17 & 17 & 18 & 90 & 40 & Mole & Rabbit \\
\hline 18 & 2 & 19 & 90 & 40 & Mole & Mole \\
\hline 19 & 19 & 20 & 90 & 40 & Squirrel & Mole \\
\hline 20 & 20 & 21 & 90 & 40 & Gopher & Mole \\
\hline 21 & 21 & 22 & 90 & 40 & Weasel & Beaver \\
\hline 22 & 3 & 23 & 90 & 50 & Squirrel & Ferret \\
\hline 23 & 23 & 24 & 420 & 100 & Mole & Mole \\
\hline 24 & 24 & 25 & 420 & 100 & Mole & Squirrel \\
\hline 25 & 6 & 26 & 60 & 25 & Mole & Mole \\
\hline 26 & 26 & 27 & 60 & 25 & Mink & Gopher \\
\hline 27 & 27 & 28 & 60 & 20 & Gopher & Gopher \\
\hline 28 & 28 & 29 & 200 & 50 & Beaver & Mole \\
\hline 29 & 29 & 30 & 200 & 50 & Mole & Mole \\
\hline 30 & 30 & 31 & 150 & 50 & Mole & Mole \\
\hline 31 & 31 & 32 & 210 & 50 & Mole & Squirrel \\
\hline 32 & 32 & 33 & 60 & 20 & Weasel & Mole \\
\hline \multicolumn{5}{|c|}{ Total life cycle costs } & $\$ 2,404,475.17$ & $\$ 1,804,009.74$ \\
\hline \multicolumn{5}{|c|}{ Net cost saving } & - & $\$ 600,465.43$ \\
\hline \multicolumn{5}{|c|}{ Cost saving percentage } & - & $25 \%$ \\
\hline
\end{tabular}

Table 3 indicates that the expensive conductor has a relatively lower value of resistance, thus allowing lower energy losses when the system has the same load condition. Therefore, there is a potential conflict between the total life span energy losses costs and the total LCCs of all conductors in the network. Figure 5 reveals this conflict and proves the proposed algorithm can successfully achieve the balance between these two conflicting costs. On the other hand, even though the wind farm in the network is considered as a zero marginal cost generator, attempting to fully consume all available output of the renewable resources in the demand side may result in high conductor investment costs or high energy losses costs. Figure 6 shows that the optimum power consumption of the wind farm in each iteration. From the results in Figure 6, it is observed that parts of the available capacity are curtailed to achieve the minimum total costs (including total energy losses costs, energy purchase costs and conductor investment costs). Based on the proposed approach, the conductor sizes that cannot satisfy the minimum and maximum voltage constraints are eliminated and replaced by the new ones that can satisfy the constraints. Figures 7 and 8 illustrate that the minimum and maximum voltage occur in each iteration and proves that the proposed approach can successfully ensure that all the conductors satisfy the voltage constraints (0.94 to 1.1 p.u.). 


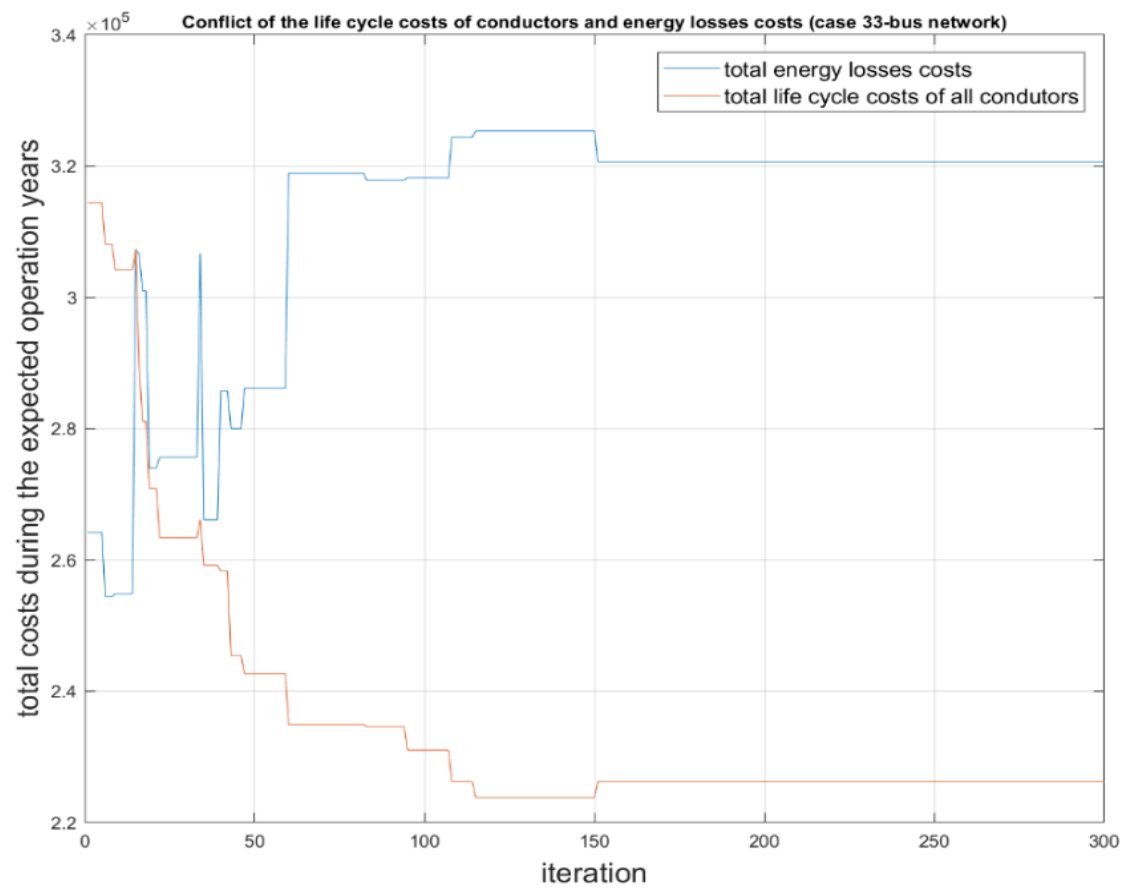

Figure 5. Conflict of the life cycle costs of conductors and energy losses costs (case 33-bus network).

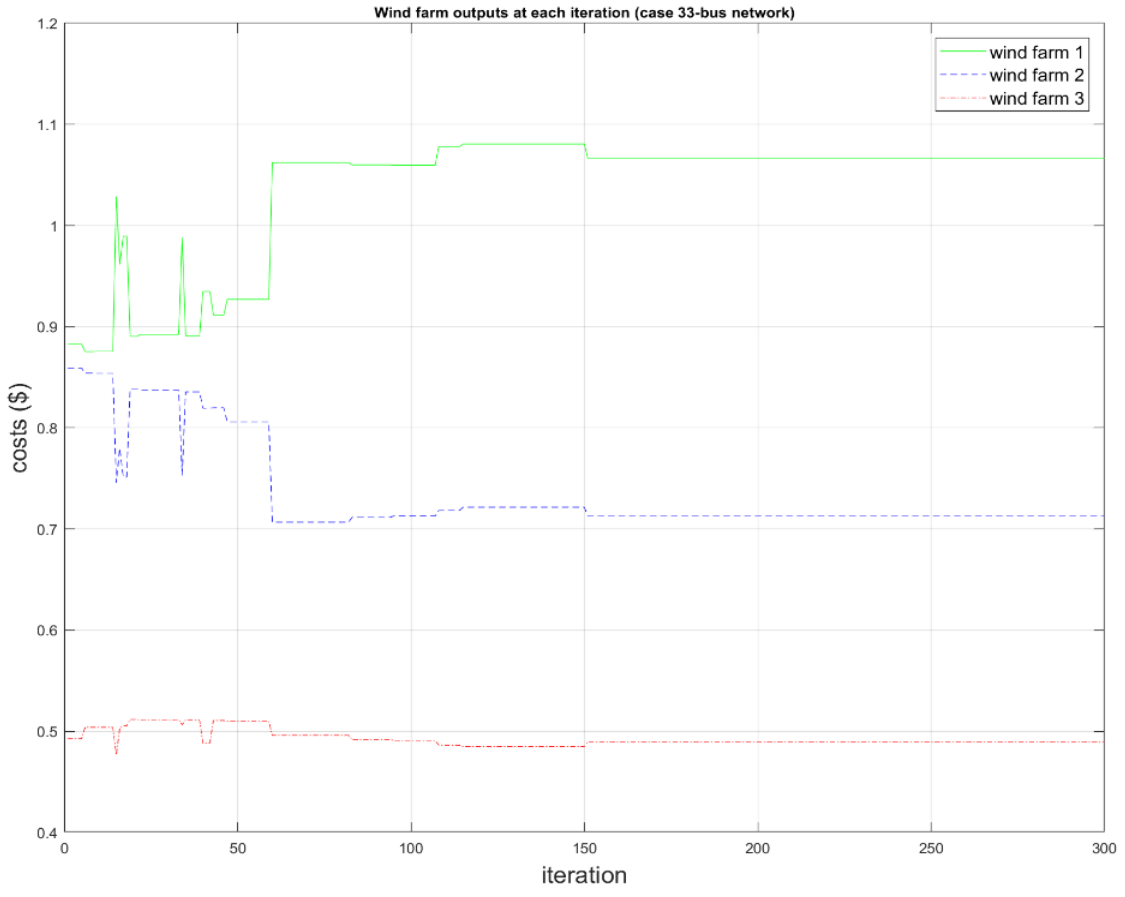

Figure 6. Wind farm output at each iteration (case 33-bus network). 


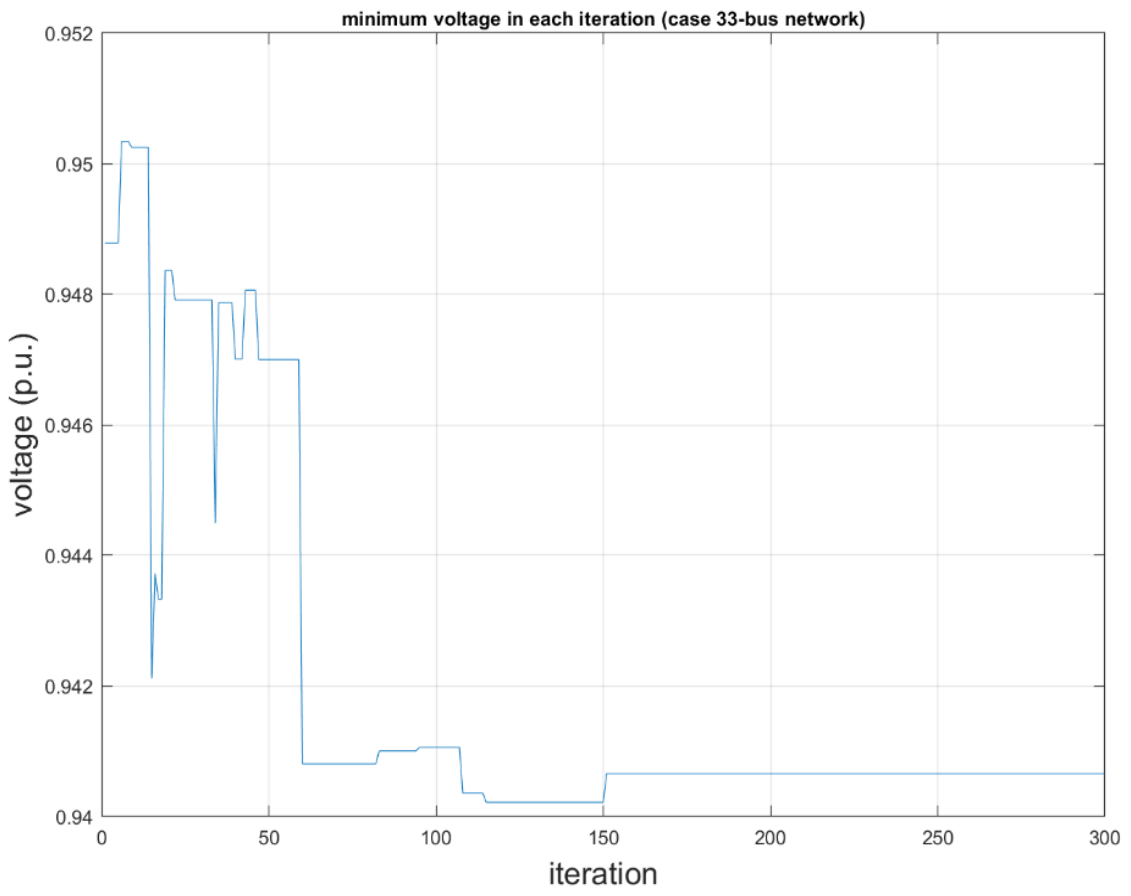

Figure 7. Minimum voltage at each iteration (case 33-bus network).

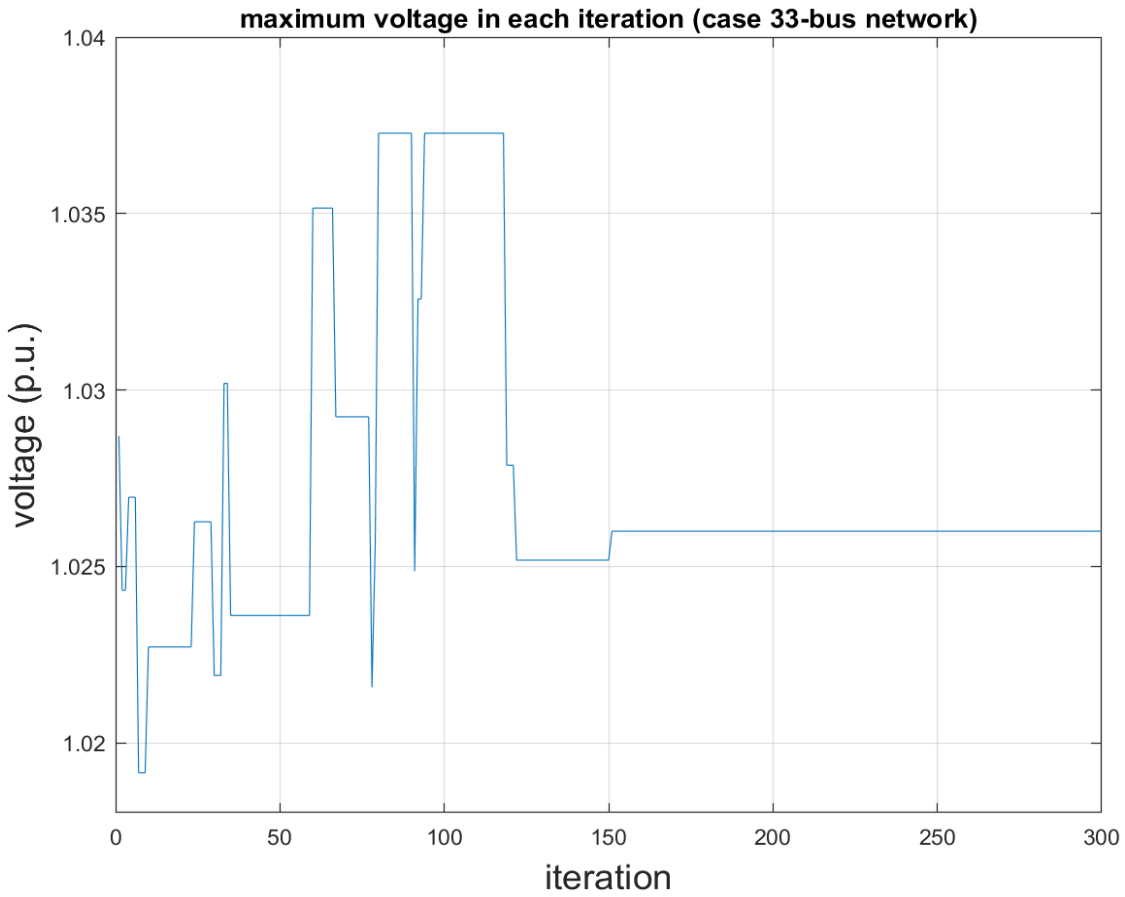

Figure 8. Maximum voltage in each iteration (case 33-bus network).

(2) Case study of the IEEE 69-bus distribution network

The proposed CCS optimization approach is tested on an IEEE 69-bus network in this section, where three wind generators are connected to the network at branch 6, branch 36 and branch 53 . The single line diagram of this 69-bus distribution network is shown in Figure 9, and the relevant operation data and network constraints are listed in Table 7. 


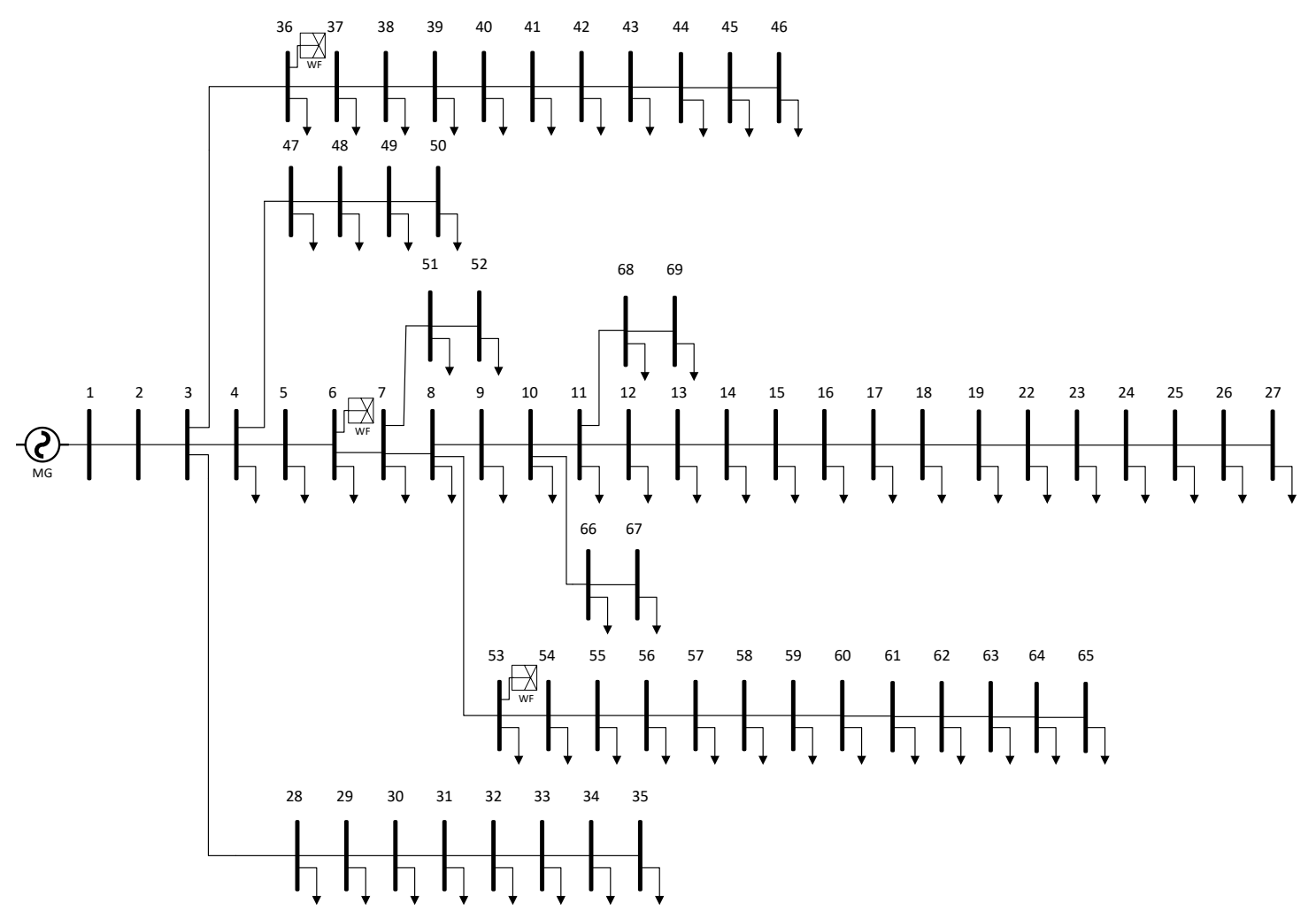

Figure 9. Single line diagram of the IEEE 69-bus distribution network.

Table 7. Parameters of the 69-bus network.

\begin{tabular}{cc}
\hline Parameter & Value \\
\hline Maximum voltage & 1.1 (p.u.) \\
Minimum voltage & 0.94 (p.u.) \\
Initial total active demand & $3.22 \mathrm{MW}$ \\
Initial total reactive demand & $1.78 \mathrm{MVar}$ \\
Load growth rate & $3 \% /$ year \\
Operation year & 20 years \\
Total branches & 68 \\
Maximum available output of wind farm at node 6 & $1.2 \mathrm{MW}$ \\
Maximum available output of wind farm at node 36 & $1.0 \mathrm{MW}$ \\
Maximum available output of wind farm at node 53 & $0.6 \mathrm{MW}$ \\
\hline
\end{tabular}

Same as the case of IEEE 33-bus network, the quadratic generation cost function of the main generator connected at node 1 is expressed in Equation (25) and the wind farm is also considered as a zero marginal cost generator in the case of 69-bus network.

The overall results of the proposed AGA optimal CSS for the selected 69-bus distribution network are shown in Figure 10. It is observed that the best fitness can be achieved after approximately 160 iterations. The mutation rate is self-adaptive during the process of the AGA, which is shown in Figure 11. It can be observed that the mutation rate is increased when the AGA cannot provide a better fitness value and resets to zero when a better fitness value is achieved. Further, it is noted that the best fitness value is captured after 250 iterations since the 69-bus system is more complicated than the 33-bus system. 


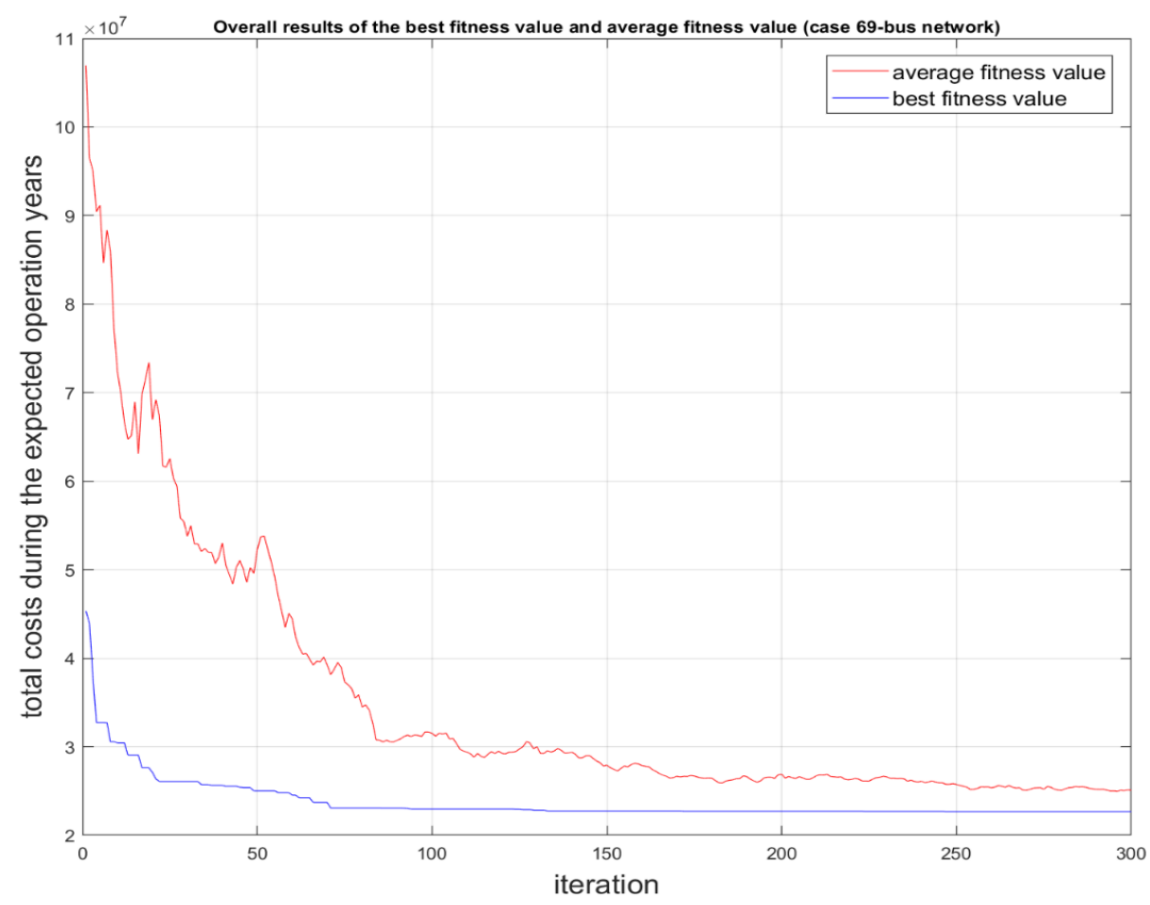

Figure 10. Overall results of the best fitness value and average fitness value (case 69-bus network).

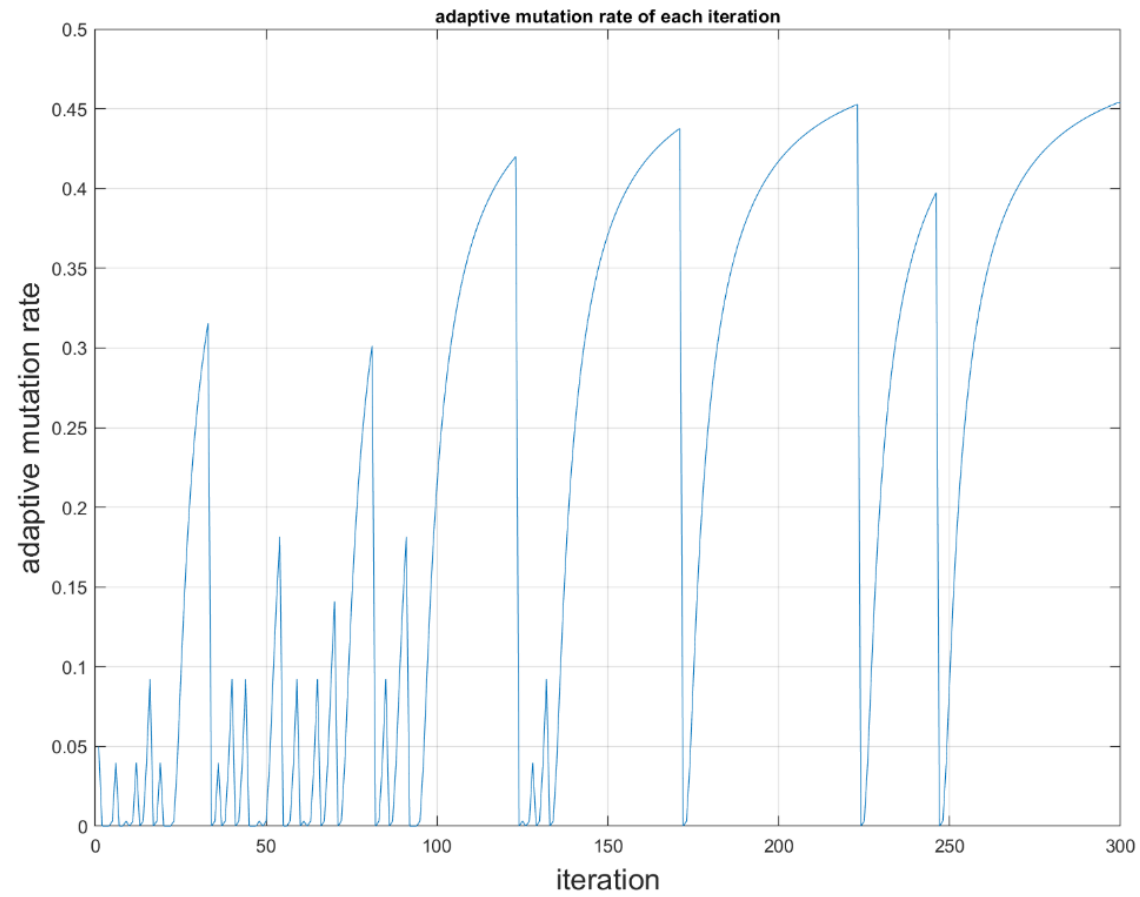

Figure 11. Adaptive mutation rate in each iteration (case 69-bus network).

Similar to the results of the 33-bus system, Figure 12 reveals the conflict between total energy losses and the life cycle costs of all conductors in the 69-bus network, thus proving that the proposed algorithm can successfully achieve the balance between these two contrary costs. Figure 13 indicates the optimum power consumption of the wind farm generations in each iteration in the case of the 69-bus system. Similar to the results in the 33-bus system, parts of the available capacity are curtailed for achieving the minimum total costs (including total energy losses costs, energy purchase costs and conductor's investment costs). 


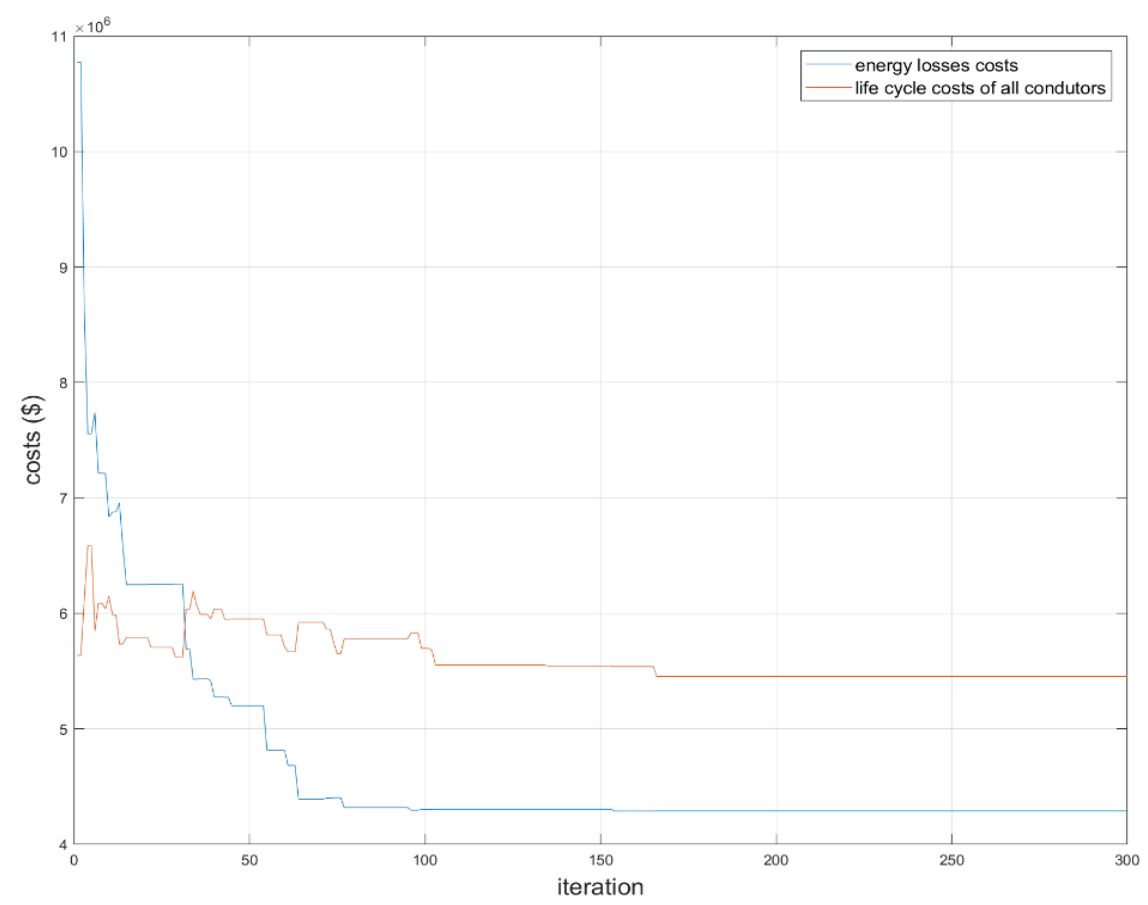

Figure 12. Conflict of the life cycle costs of conductors and energy losses costs (case 69-bus network).

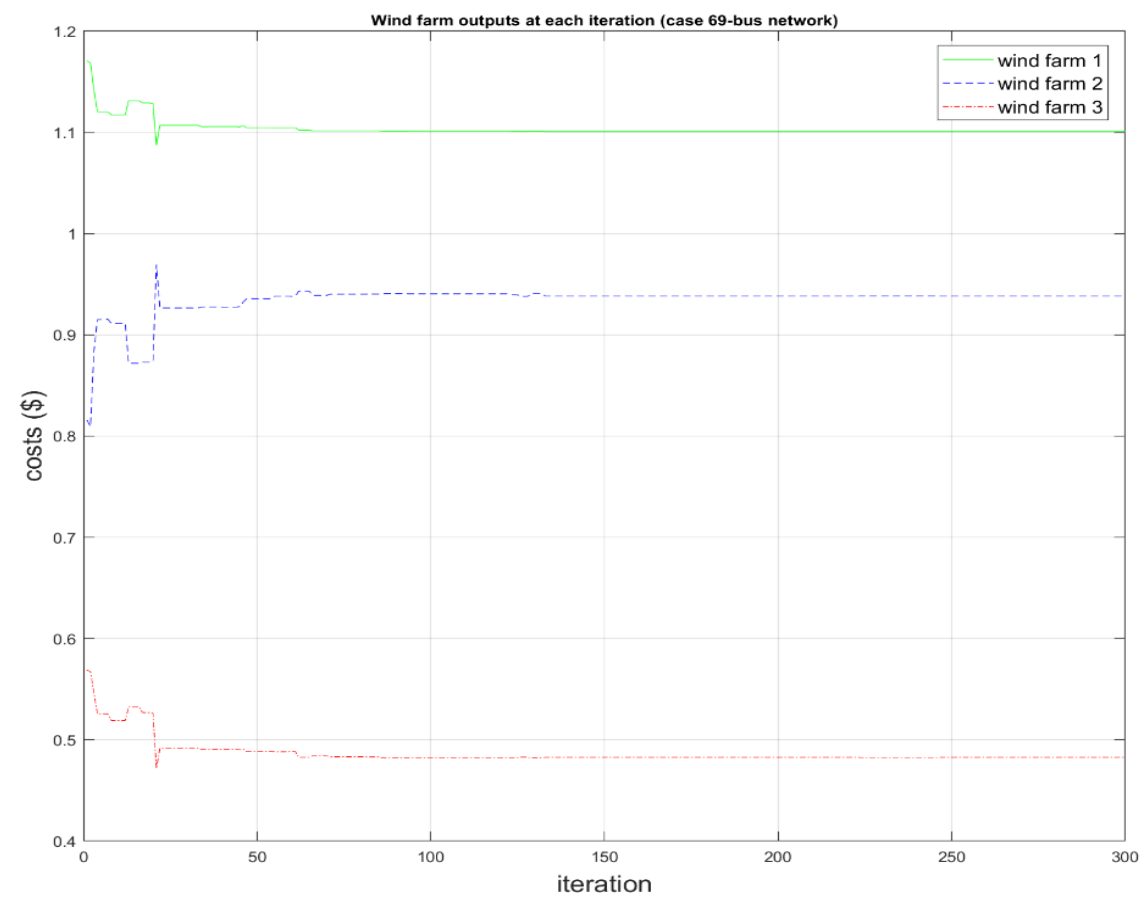

Figure 13. Wind farm outputs at each iteration (case 69-bus network).

Similar to the results in the case study of the 33-bus network, the individuals that cannot satisfy the minimum and maximum voltage constraints are eliminated and replaced by the new individuals that can satisfy the constraints. Figures 14 and 15 illustrate that the minimum and maximum voltage occur in each iteration and proves that the proposed approach can successfully ensure all the individuals satisfy the voltage constraints (0.94 to 1.1 p.u.). 


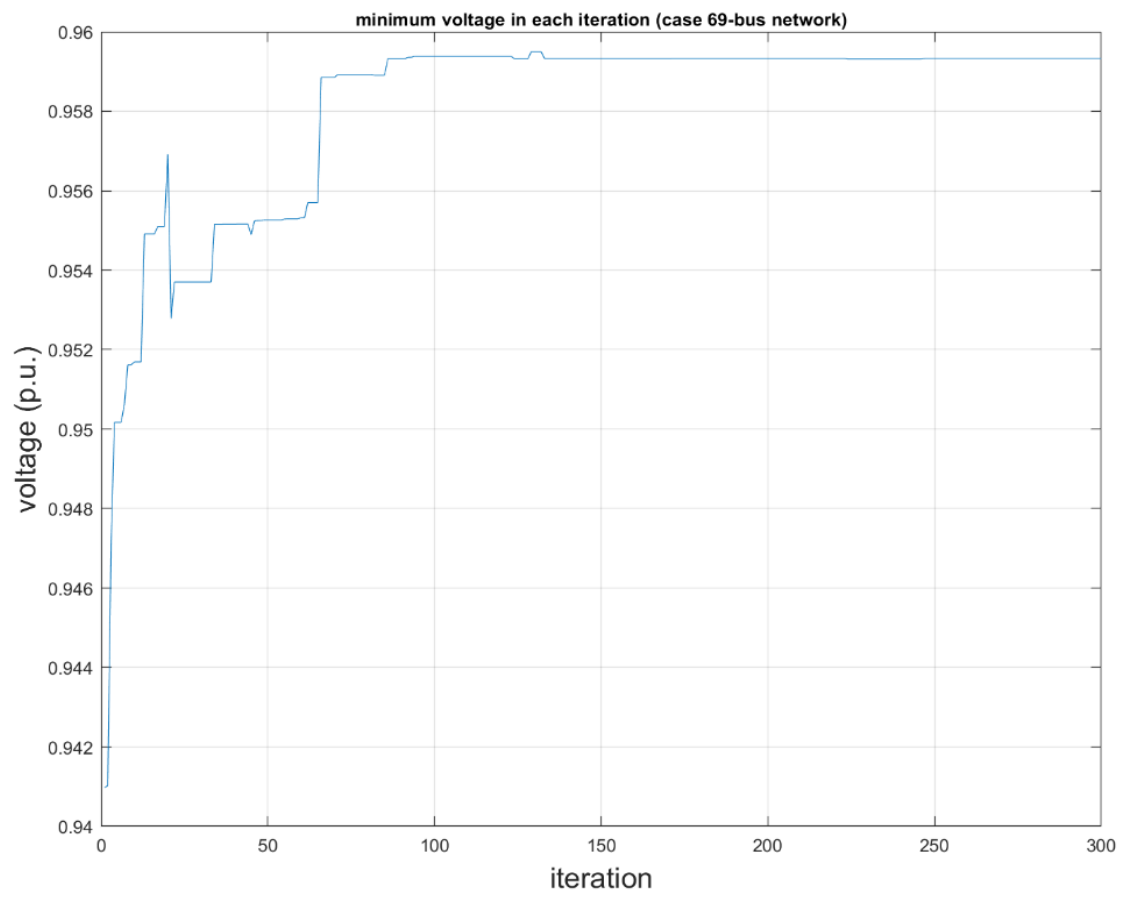

Figure 14. Minimum voltage at each iteration (case 69-bus network).

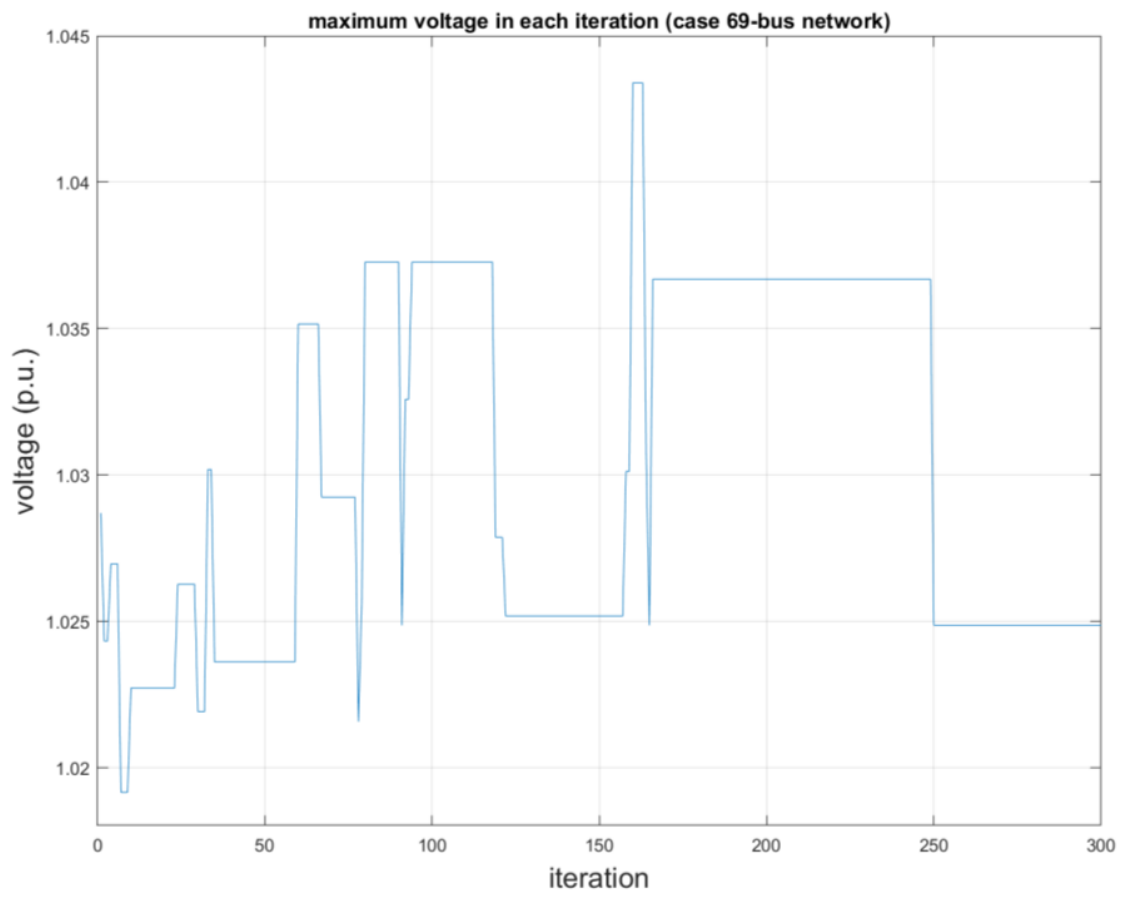

Figure 15. Maximum voltage in each iteration (case 69-bus network).

The detailed optimum results of CSS by two different approaches are shown in Table 8. After the decoding process, the best conductor type of each branch in the 69-bus network can be checked on this table. 
Table 8. Best CSS for 69-bus distribution network.

\begin{tabular}{|c|c|c|c|c|c|c|c|c|c|}
\hline Branch & From & To & $\begin{array}{c}\text { Selected } \\
\text { Conductor } \\
\text { Type via } \\
\text { Standard GA }\end{array}$ & $\begin{array}{c}\text { Selected } \\
\text { Conductor } \\
\text { Type via AGA }\end{array}$ & Branch & From & To & $\begin{array}{c}\text { Selected } \\
\text { Conductor } \\
\text { Type via } \\
\text { Standard GA }\end{array}$ & $\begin{array}{c}\text { Selected } \\
\text { Conductor } \\
\text { Type via AGA }\end{array}$ \\
\hline 2 & 2 & 3 & Weasel & Ferret & 36 & 36 & 37 & Squirrel & Otter \\
\hline 3 & 3 & 4 & Mole & Otter & 37 & 37 & 38 & Gopher & Ferret \\
\hline 4 & 4 & 5 & Ferret & Otter & 38 & 38 & 39 & Mole & Gopher \\
\hline 7 & 7 & 8 & Rabbit & Beaver & 41 & 41 & 42 & Squirrel & Ferret \\
\hline 8 & 8 & 9 & Gopher & Otter & 42 & 42 & 43 & Ferret & Rabbit \\
\hline 9 & 9 & 10 & Weasel & Mink & 43 & 43 & 44 & Rabbit & Mink \\
\hline 10 & 10 & 11 & Mink & Otter & 44 & 44 & 45 & Gopher & Weasel \\
\hline 11 & 11 & 12 & Gopher & Rabbit & 45 & 45 & 46 & Mink & Gopher \\
\hline 16 & 16 & 17 & Mole & Raccoon & 50 & 8 & 81 & Gopher & Rabbit \\
\hline 17 & 17 & 18 & Gopher & Rabbit & 51 & 51 & 52 & Beaver & Squirrel \\
\hline 18 & 18 & 19 & Squirrel & Mole & 52 & 9 & 53 & Gopher & Raccoon \\
\hline 19 & 19 & 20 & Squirrel & Squirrel & 53 & 53 & 54 & Mink & Beaver \\
\hline 20 & 20 & 21 & Squirrel & Weasel & 54 & 54 & 55 & Mole & Mink \\
\hline 21 & 21 & 22 & Mink & Raccoon & 55 & 55 & 56 & Squirrel & Raccoon \\
\hline 22 & 22 & 23 & Mole & Mink & 56 & 56 & 57 & Mole & Beaver \\
\hline 23 & 23 & 24 & Gopher & Weasel & 57 & 57 & 58 & Rabbit & Otter \\
\hline 24 & 24 & 25 & Beaver & Mole & 58 & 58 & 59 & Mole & Otter \\
\hline 25 & 25 & 26 & Rabbit & Squirrel & 59 & 59 & 60 & Rabbit & Raccoon \\
\hline 26 & 26 & 27 & Weasel & Weasel & 60 & 60 & 61 & Weasel & Otter \\
\hline 27 & 3 & 28 & Weasel & Mole & 61 & 61 & 62 & Mole & Ferret \\
\hline \multicolumn{5}{|c|}{ Total life-cycle costs of two approaches } & \multicolumn{3}{|c|}{$\begin{array}{c}\text { Standard GA } \\
\text { Proposed AGA }\end{array}$} & \multicolumn{2}{|c|}{$\begin{array}{l}\$ 39,054,123.9 \\
\$ 27,617,228.5\end{array}$} \\
\hline \multicolumn{5}{|c|}{ Net cost saving } & \multicolumn{3}{|c|}{-} & \multicolumn{2}{|c|}{$\$ 11,436,895.4$} \\
\hline \multicolumn{5}{|c|}{ Cost saving percentage } & \multicolumn{3}{|c|}{ - } & \multicolumn{2}{|c|}{$29 \%$} \\
\hline
\end{tabular}

\section{(3) Summary and discussion}

The study results of the 33-bus network and the 69-bus network indicate that the proposed AGA has the capability to provide a more efficient and effective way to solve the new challenge in the CSS problem than the standard GA. In particular, $25 \%$ and $29 \%$ total costs saving are achieved separately by the proposed approach in two different distribution networks. More importantly, the potential economic conflict between the investment of conductors and the renewable recourses curtailment costs is firstly considered in the CCS problem. On the other hand, the proposed approach employs a comprehensive conductor investment and O\&M pricing model to provide precise and practical study results. The simulation times of the proposed AG and the standard GA used in the framework are summarized in Table 9 to identify the efficiency of these two approaches. The results indicate that the calculation time is slightly increased when the proposed AGA is applied. However, the proposed AGA has the capability to provide a better solution to the CSS problem. In addition, the information about our computing platform used to assess the simulation results is listed below.

Table 9. Simulation times of standard GA and proposed AGA.

\begin{tabular}{ccc}
\hline Simulation Times & Standard GA & Proposed AGA \\
\hline Case 33-bus network & $669.42 \mathrm{~s}$ & $720.35 \mathrm{~s}$ \\
Case 69-bus network & $1548.76 \mathrm{~s}$ & $2078.81 \mathrm{~s}$ \\
\hline
\end{tabular}


The computing platform used in this paper:

CPU: i5-8600k (Max Turbo Frequency $4.30 \mathrm{GHz}$ )

Memory: 32 GB (2400 MHz)

Graphic card: Nvidia RTX 2080

\section{Conclusions}

A hybrid optimization algorithm to deal with the CSS problems in distribution systems with high penetration of DG has been proposed in this paper. An AGA that has a dynamic mutation rate and a dynamic number of mutated genes has been introduced as the main optimization mechanism. The proposed AGA mechanism is responsible for finding the optimal CSS for the chosen network and the objective function is to minimize the sum of the LCC of selected conductors, the total energy procurement costs and energy losses costs. It is noted that the total energy procurement costs and energy losses costs of each individual are provided by the AC-OPF, which is employed as the auxiliary optimization tool in the approach.

The numerical results have demonstrated an ability to provide accurate and feasible solutions for solving the optimal CSS problem and ensured that the results satisfy the network constraints. Different from the majority of earlier research of the CSS problem, this approach comprehensively considers the ED problems of the traditional fossil fuel generator and the renewable resources. Instead of the objective function of minimum energy losses costs, the minimum system level costs are considered as the main target in this approach.

The development of the high capacity electric vehicle charging stations and electrical storage system significantly affect the planning of the distribution networks. The CSS problem is expected to be considered by those technologies. On the other hand, the high penetration of DGs will significantly change the short-circuit currents through the distribution systems. This feature may affect the selection of conductors when the DNOs consider a network upgrading plan. Indeed, several approaches are able to deal with this potential problem when the DNOs design or upgrade their distribution networks such as application of the superconducting fault current limiter (SFCL) or installing the second circuit break (CBs) in the proper place. However, the potential conflict between the costs of a second circuit break or superconducting fault current limiter and the costs of conductors upgrading requires careful investigation. Therefore, the potential problem of increasing short-circuit currents caused by high penetration of DGs will also be incorporated in future research.

Author Contributions: Writing and original draft preparation, Z.Z.; Review and editing, J.M.

Funding: This research received no external funding.

Conflicts of Interest: The authors declare no conflict of interest.

\section{References}

1. Gielen, D.; Boshell, F.; Saygin, D.; Bazilian, M.D.; Wagner, N.; Gorini, R. The role of renewable energy in the global energy transformation. Energy Strateg. Rev. 2019, 24, 38-50. [CrossRef]

2. Fan, A.; Huang, L.; Lin, S.; Chen, N.; Zhu, L.; Wang, X. Performance Comparison Between Renewable Obligation and Feed-in Tariff with Contract for Difference in UK. In Proceedings of the 2018 China International Conference on Electricity Distribution (CICED), Tianjin, China, 17-19 September 2018; pp. 2761-2765.

3. Pandey, R.R.; Arora, S. Distributed generation system: A review and its impact on India. Int. Res. J. Eng. Technol. 2016, 3, 758-765.

4. Kamaruzzaman, Z. Effect of grid-connected photovoltaic systems on static and dynamic voltage stability with analysis techniques-A review. Prz. Elektrotechniczny 2015, 1, 136-140. [CrossRef]

5. Funkhouser, A.W.; Huber, R.P. A Method for Determining Economical ACSR Conductor Sizes for Distribution Systems [includes discussion]. Trans. Am. Inst. Electr. Eng. Part III Power Appar. Syst. 1955, 74, 479-484. [CrossRef] 
6. Wang, Z.; Liu, H.; Yu, D.C.; Wang, X.; Song, H. A practical approach to the conductor size selection in planning radial distribution systems. IEEE Trans. Power Deliv. 2000, 15, 350-354. [CrossRef]

7. Sivanagaraju, S.; Sreenivasulu, N.; Vijayakumar, M.; Ramana, T. Optimal conductor selection for radial distribution systems. Electr. Power Syst. Res. 2002, 63, 95-103. [CrossRef]

8. Franco, J.F.; Rider, M.J.; Lavorato, M.; Romero, R. Optimal Conductor Size Selection and Reconductoring in Radial Distribution Systems Using a Mixed-Integer LP Approach. IEEE Trans. Power Syst. 2013, 28, 10-20. [CrossRef]

9. Legha, M.M. Combination of optimal conductor selection and capacitor placement in radial distribution systems using PSO method. Iraqi J. Electr. Electron. Eng. 2014, 10, 33-41.

10. Haidar, S.; Legha, M.M. Optimal Conductor Selection in Radial Distribution Using Imperialism Competitive Algorithm and Comparison with PSO Method. In Proceedings of the 6th International Conference for Scientific Computing to Computational Engineering, Athenes, Greece, 9-12 July 2014.

11. Devi, A.L.; Shereen, A. Optimal conductor selection for radial distribution networks using genetic algorithm in SPDCL, AP-A case study. J. Theor. Appl. Inf. Technol. 2009, 6, 674-685.

12. Vahid, M.; Hossein, A.A.; Kazem, M. Maximum loss reduction applying combination of optimal conductor selection and capacitor placement in distribution systems with nonlinear loads. In Proceedings of the 2008 43rd International Universities Power Engineering Conference, Padova, Italy, 1-4 September 2008; pp. 1-5.

13. Falaghi, H.; Singh, C. Optimal Conductor Size Selection in Distribution Systems with Wind Power Generation. In Wind Power Systems: Applications of Computational Intelligence; Wang, L., Singh, C., Kusiak, A., Eds.; Springer: Berlin/Heidelberg, Germany, 2010; pp. 25-51.

14. Thenepalle, M. A comparative study on optimal conductor selection for radial distribution network using conventional and genetic algorithm approach. Int. J. Comput. Appl. 2011, 6, 6-13. [CrossRef]

15. Abdelaziz, A.Y.; Fathy, A. A novel approach based on crow search algorithm for optimal selection of conductor size in radial distribution networks. Eng. Sci. Technol. An Int. J. 2017, 20, 391-402. [CrossRef]

16. Rao, R.S.; Satish, K.; Narasimham, S.V.L. Optimal Conductor Size Selection in Distribution Systems Using the Harmony Search Algorithm with a Differential Operator. Electr. Power Compon. Syst. 2011, 40, 41-56. [CrossRef]

17. Holland, J.H. Adaptation in Natural and Artificial Systems: An Introductory Analysis with Applications to Biology, Control and Artificial Intelligence; MIT Press: Cambridge, MA, USA, 1992; p. 228.

18. Liu, J.; Cai, Z.; Liu, J. Premature convergence in genetic algorithm: Analysis and prevention based on chaos operator. In Proceedings of the 3rd World Congress on Intelligent Control and Automation, Hefei, China, 26 June-2 July 2000; Volume 491, pp. 495-499.

19. Hrstka, O.; Kučerová, A. Improvements of real coded genetic algorithms based on differential operators preventing premature convergence. Adv. Eng. Softw. 2004, 35, 237-246. [CrossRef]

20. Pandey, H.M.; Chaudhary, A.; Mehrotra, D. A comparative review of approaches to prevent premature convergence in GA. Appl. Soft Comput. 2014, 24, 1047-1077. [CrossRef]

21. Queiroz, L.M.O.; Lyra, C. Adaptive Hybrid Genetic Algorithm for Technical Loss Reduction in Distribution Networks under Variable Demands. IEEE Trans. Power Syst. 2009, 24, 445-453. [CrossRef]

22. Eiben, A.E.; Hinterding, R.; Michalewicz, Z. Parameter control in evolutionary algorithms. IEEE Trans. Evol. Comput. 1999, 3, 124-141. [CrossRef]

23. Mahmoodabadi, M.J.; Nemati, A.R. A novel adaptive genetic algorithm for global optimization of mathematical test functions and real-world problems. Eng. Sci. Technol. Int. J. 2016, 19, 2002-2021. [CrossRef]

24. Ismael, S.M.; Abdel Aleem, S.H.E.; Abdelaziz, A.Y.; Zobaa, A.F. Optimal Conductor Selection of Radial Distribution Feeders: An Overview and New Application Using Grasshopper Optimization Algorithm. In Classical and Recent Aspects of Power System Optimization; Zobaa, A.F., Abdel Aleem, S.H.E., Abdelaziz, A.Y., Eds.; Academic Press: Cambridge, MA, USA, 2018; Chapter 8, pp. 185-217.

(C) 2019 by the authors. Licensee MDPI, Basel, Switzerland. This article is an open access article distributed under the terms and conditions of the Creative Commons Attribution (CC BY) license (http://creativecommons.org/licenses/by/4.0/). 